D) Check for updates

Cite this: Food Funct., 2018, 9, 4085

\section{Modulation of intestinal epithelium homeostasis by extra virgin olive oil phenolic compounds}

\author{
Monica Deiana, (D)*a Gessica Serra ${ }^{\mathrm{b}}$ and Giulia Corona ${ }^{\mathrm{c}}$
}

Received 21st February 2018, Accepted 27th July 2018

DOI: $10.1039 / \mathrm{c} 8 \mathrm{fo} 00354 \mathrm{~h}$

rsc.li/food-function

\begin{abstract}
Dietary habits have been strongly linked to the maintenance of intestinal epithelium homeostasis, whose alteration may contribute to the pathogenesis of inflammatory diseases and cancer. Polyphenols are among those dietary components suggested to be beneficial for gut health. Within a balanced Mediterranean type diet, a good portion of ingested polyphenols comes from olives and extra virgin olive oil (EVOO). Most of them reach the intestine, where they may be directly absorbed or metabolized under absorption. Others undergo an extensive gastrointestinal biotransformation, producing various metabolites that retain the potential beneficial effect of the parent compounds, or exert a more efficient biological action themselves. Ingested EVOO polyphenols (EVOOP) and their metabolites will be particularly concentrated in the intestinal lumen, where they might exert a significant local action. In this review we summarize the few studies that investigated the effect of EVOOP at the intestinal level, focusing on the possible mechanism of action in relation to their interaction with the microbiota, and their ability to potentially modulate the oxidative status of the intestinal epithelial layer, inflammation and immune response.
\end{abstract}

\section{Introduction}

The intestinal epithelium is a physical and biochemical barrier with a huge surface area, and defines the boundary between intestinal tissues and the external environment. The intestinal epithelium is specialized for nutrient and water absorption, and intestinal homeostasis depends on complex interactions among the intestinal epithelium, local and systemic immune factors, and the microbial content of the gut.

A deregulation of this equilibrium may contribute to the pathogenesis of inflammatory diseases and cancer. Dietary components strongly influence intestinal epithelium homeostasis; the "Western diet" has been associated with an elevated risk of developing intestinal diseases, as it alters the intestinal microbiota, increases intestinal permeability and promotes inflammation. Other dietary components, such as those characteristic of the Mediterranean diet, whole-grain foods, fruits, vegetables and derived products such as wine and extra virgin olive oil (EVOO), have been proved to be beneficial for gut health. ${ }^{1}$ They are rich in bioactive compounds such as polyphenols, potentially able to exert antioxidant, anti-inflammatory and prebiotic effects at the intestinal level. ${ }^{2}$ The average intake of polyphenols is approximately $1 \mathrm{~g}$ day $^{-1} .^{3}$

\footnotetext{
${ }^{a}$ Department of Biomedical Sciences, University of Cagliari, Cagliari, Italy. E-mail: mdeiana@unica.it; Fax: +39070 6754032; Tel: +39070 6754126 ${ }^{b}$ Department of Food and Nutritional Sciences, University of Reading, RG6 6AP, Reading, UK

${ }^{c}$ Health Sciences Research Centre, University of Roehampton, SW15 4JD London, UK
}

Most of them are poorly absorbed and directly or through the bile reach the colon, where they concentrate up to several hundred $\mu \mathrm{M},{ }^{3}$ in the parental form or partly metabolized form. Thus, as suggested years ago by Halliwell, ${ }^{4}$ it is likely that in this site they exert a significant local action. Although the concentration of polyphenols is higher in the intestine than elsewhere, the number of studies that investigated their effect at the intestinal level is quite limited.

Even more limited are studies specifically regarding EVOOP. Only few human studies have evaluated the effect of EVOOP on intestinal homeostasis; most have been performed on intestinal cell lines and on experimental colitis animal models. Therefore, there is limited in vivo evidence showing a beneficial effect of EVOOP in humans at the intestinal level, and we may only speculate on a protective role based on what is suggested by experimental models and observational trials.

\section{Extra virgin olive oil polyphenols}

EVOO is obtained solely through physical means by mechanical or direct pressing of olives. It is not subjected to any treatment except washing, decantation, centrifugation and filtration. The oil produced from this first press is known as EVOO; it is of the highest quality and it also contains the highest levels of beneficial constituents. ${ }^{5,6}$ The olive oil chemical composition consists of major components (triacylglycerol) that represent about $98-99 \%$ of the total oil weight, mainly oleic acid (MUFA) much higher (55-83\%) than that of the 
other fatty acids (linoleic, palmitic, or stearic acids), which ranges between $3 \%$ and $21 \%$. The minor components are present in small amounts (about $2 \%$ of oil weight) and include more than 230 chemical compounds such as hydrocarbons (squalene), phytosterols ( $\beta$-sitosterol, stigmasterol, and campesterol), tocopherols ( $\alpha$-tocopherol), carotenoids ( $\beta$-carotene), coloring pigments (chlorophylls), aliphatic and triterpenic alcohols, volatile compounds and phenolics, such as tyrosol (TYR) and hydroxytyrosol (HT) ${ }^{7-9}$

The phenolic fraction of EVOO is heterogeneous, with at least 36 structurally distinct phenolic compounds identified that can be grouped into the following classes:

- Phenolic acids. They can be divided into three subgroups: hydroxybenzoic acids, such as gallic, protocatechuic, and 4-hydroxybenzoic acids; hydroxycinnamic acids, such as caffeic, vanillin, syringic, $p$-coumaric, and $o$-coumaric acids; and other phenolic acids and derivatives. These compounds are generally present in small amounts (<10 mg per $\mathrm{kg}$ of oil). ${ }^{10}$

- Phenolic alcohols. These compounds possess a hydroxyl group attached to an aromatic hydrocarbon group, HT (3,4dihydroxyphenyl-ethanol or 3,4-DHPEA) and TYR ( $p$-hydroxyphenyl-ethanol or $p$-HPEA). Their concentration is usually low in fresh oils but increases during oil storage due to the hydrolysis of EVOO secoiridoids (ranging from 0 to $70 \mathrm{mg}$ per $\mathrm{kg}$ of oil). ${ }^{10-12}$

- Secoiridoids. This phenolic group is characterized by the presence of either elenolic acid or elenolic acid derivatives in their molecular structure. ${ }^{11,13}$ The most abundant are the dialdehydic form of decarboxymethyl elenolic acid linked to HT (3,4-DHPEA) or TYR ( $p$-HPEA) (3,4-DHPEA-EDA or $p$-HPEA-EDA), oleuropein (OL), its isomer, OL aglycon (HT linked to elenolic acid) (3,4-DHPEA-EA), and ligstroside aglycon (TYR linked to elenolic acid) ( $p$-HPEA-EA). $p$-HPEA derivates and dialdehydic forms of OL and ligstroside aglycon were also detected as minor hydrophilic phenols of EVOO. ${ }^{14}$

- Hydroxy-isocromans. This is a class of phenolic compounds recently characterized of EVOO and the presence of 1-phenyl-6,7-dihydroxy-isochroman and 1-(39-methoxy-49hydroxy) phenyl-6,7-dihydroxy-isochroman has been shown in several samples. ${ }^{15}$

- Flavonoids: These polyphenolic compounds contain two benzene rings joined by a linear three carbon chain and apigenine, luteoline, and (+)-taxifoline are the most concentrated. The amount of these compounds in EVOO is very low and generally ranges between 0 and $10 \mathrm{mg}$ per $\mathrm{kg}$ of oil. ${ }^{16}$

- Lignans: The exact structure of this type of phenolic is not well understood but it is based on aromatic aldehyde condensation. (+)-1-Pinoresinol, (+)-1-acetoxypinoresinol and hydroxypinoresinol were characterized as the most concentrated lignans in EVOO. ${ }^{17}$ These compounds are present in the pulp and in the woody portion of the seed. ${ }^{18}$

TYR, HT, and their secoiridoid derivatives make up around $90 \%$ of the total phenolic content of EVOO. ${ }^{19}$ Not all phenolics are present in every EVOO and considerable variation has been noted in the concentration of such phenolic compounds (50 to $\left.1000 \mathrm{mg} \mathrm{kg}^{-1}\right){ }^{5,20,21}$
The EVOO phenolic content is determined by several factors such as olive variety (cultivar), growing area, fruit ripening, cultivation techniques, processing and storage conditions. $^{22-24}$

\section{Metabolism and bioavailability}

The metabolic fate of phenolic compounds after ingestion has been the subject of several studies by the scientific community to find out the mechanisms through which they exert their activity in the organism. Indeed, the bioavailability of EVOOP is the key in achieving an effect in specific tissues or organs. $^{25,26}$

Most of the studies regarding the bioavailability of these compounds have focused on the two most abundant EVOO simple phenolics: HT and TYR, amongst a few others. ${ }^{27}$ After ingestion, EVOOP can be partially modified in the acidic environment of the stomach. The effect of such an environment on aglycone secoiridoids has been examined in vitro by incubating the compounds at $37{ }^{\circ} \mathrm{C}$ under simulated gastric $\mathrm{pH}$ conditions ( $\mathrm{pH} 2.0$ ) and during normal physiological time frames (up to $4 \mathrm{~h}$ ). ${ }^{28,29}$ Although hydrolysis takes place releasing free phenolic alcohols, a significant amount remains intact and thus, enters the small intestine unhydrolyzed. However, OL aglycone and its dialdehydic form are likely not absorbed as such in the small intestine; in fact, the major metabolites detected using a perfused rat intestinal model were the glucuronide conjugates of the reduced form of both compounds. ${ }^{29}$ In contrast, if the ingested secoiridoid is glucosylated it appears not to be subjected to gastric hydrolysis, ${ }^{30}$ meaning that phenolics such as the glucosides of OL enter the small intestine unmodified, along with high amounts of free HT and TYR and remaining secoiridoid aglycones.

Research evidence demonstrates that EVOOP are significantly absorbed ( $40 \%-95 \%)$ in a dose-dependent manner in humans $^{30-37}$ and the major site for the absorption of these compounds is the small intestine. ${ }^{30,32,38-40}$

There are different mechanisms by which absorption occurs with regard to EVOOP. The different polarities of the various phenolics have been postulated to play a role in the absorption of these compounds. ${ }^{30}$ For instance, TYR and HT are polar compounds and their absorption has been shown to occur by a bidirectional passive diffusion mechanism across the membrane of the human enterocytes. ${ }^{41}$ Other EVOOP, such as $p$-coumaric acid, pinoresinol, luteolin ${ }^{25}$ and HT acetate ${ }^{42}$ have shown the same mechanism of transport.

Larger compounds may be absorbed via a different mechanism to that of TYR and HT. It has been proposed that the polar but larger OL glycoside may diffuse through the lipid bilayer of the epithelial cell membrane and be absorbed via a glucose transporter, but, potentially also via the paracellular route or transcellular passive diffusion. ${ }^{43}$ Despite being well absorbed, the bioavailability of EVOOP is scarce due to an extensive pre-systemic first-pass metabolism in the gut and liver. $^{27}$ 
Once absorbed, EVOOP are, in fact, subjected to three main types of conjugation: methylation, glucuronidation and sulfation, through the respective action of catechol-O-methyl transferases (COMT), uridine-5'-diphosphate glucuronosyltransferases (UDPGT) and sulfotransferases (SULT). ${ }^{44}$

Different studies showed that HT and TYR can be metabolized to $O$-glucuronidated conjugates, ${ }^{31,33,40,45,46}$ but HT also undergoes $O$-methylation, and both homovanillic acid (HVA) and homovanillyl alcohol (HVAlc) have been detected in human and animal plasma and urine after the oral administration of either EVOO or pure HT and TYR. ${ }^{34,40,47-49}$

The urinary excretion of HVAlc and HVA in humans was reported for the first time by Caruso et al. ${ }^{45}$ after the intake of different EVOOs (the lowest administered dose was $7 \mathrm{mg}$ of total HT per $50 \mathrm{~mL}$ oil, and the maximum provided about $23 \mathrm{mg}$ per $50 \mathrm{~mL}$ oil). HVAlc contributes to $22 \%$ of the total excretion of HT and its metabolites, and HVA 56\%. The excretion of both metabolites correlated with the administered dose of HT. Even at low doses, HVAlc and HVA were excreted. In a later study, Miro-Casas et al. ${ }^{39}$ observed how the urinary amounts of HT and HVAlc increased in response to EVOO ingestion, reaching the maximum peak at 0-2 $\mathrm{h}$. Urinary recovery $12 \mathrm{~h}$ after olive oil ingestion showed that $65 \%$ of HT was in its glucurono-conjugated form and $35 \%$ in other conjugated forms.

The urinary concentrations and excretion rates of the glucuronides of EVOOP were also successfully estimated in a study carried out by Khymenets et al. ${ }^{46}$ using a dietary dose of EVOO $(50 \mathrm{~mL})$. About $13 \%$ of the consumed EVOOP were recovered in $24 \mathrm{~h}$ urine, where $75 \%$ of them were in the form of glucuronides (30- and 40-O-HT glucuronides, 40-O-glucuronides of TYR) and 25\% as free compounds.

A study conducted by Corona et $a l .{ }^{28}$ on the absorption, metabolism and microflora-dependent transformation of HT, TYR and their conjugated forms (e.g. OL) also showed similar results; both HT and TYR, transferred across the human Caco-2 cell monolayers and rat segments of the jejunum and ileum, were subject to classic phase I/II biotransformation. The major gastrointestinal metabolites identified were an $O$-methylated derivative of HT, glucuronides of HT and TYR and a novel glutathionylated conjugate of HT (HT-GSH). In contrast, there was no absorption of OL in either model. ${ }^{28}$

On the other hand, sulfation can occur after gastrointestinal absorption; in fact in different studies conducted testing phenol-enriched virgin olive oils, ${ }^{37,50,51}$ sulfation was the main conjugation pathway for EVOOP, whereas the glucuronidated forms were not detected. The main phenolic metabolites detected in plasma samples after the ingestion of EVOO were HT sulfate, HT acetate sulfate, HVA and HVA sulfate. HT sulfate appears to be a good biomarker for monitoring the compliance of EVOO intake and a very recent study using pure $\mathrm{HT}^{52}$ seems to reinforce this notion. In this last study, quantitatively, the total amount of HT recovered in the urine was minimal and accounted for $0.02 \%$ (only for the $25 \mathrm{mg}$ dose). For the metabolites, they observed a dose-dependent increase in their excretion. And the major metabolite detected was HT 3-sulphate, which accounted for $23.1 \%$ (for the $5 \mathrm{mg}$ dose) and $16.6 \%$ (for the $25 \mathrm{mg}$ dose) of the administered HT, followed by HT 3-O-glucuronide with $2.78 \%$ (for the $5 \mathrm{mg}$ dose) and $2.87 \%$ (for the $25 \mathrm{mg}$ dose).

Suárez et $a l .{ }^{53}$ considered for the first time the absorption and disposition of flavonoids and lignans after the ingestion of EVOO. Besides the presence of these EVOOP in their conjugated forms, an important variability in the concentrations was observed between the plasma samples obtained from different volunteers. This variability may be attributed to differences in the expression of metabolizing enzymes due to genetic variability within the population. ${ }^{53}$

Also De Bock et al. noted a large inter-individual variation in the absorption and metabolism of phenolic compounds in a study with olive leaf extract administration in humans, possibly resulting from the differences in human enzymatic activity. For example, males may be more efficient at conjugating OL, which would explain their lower area under the curve (AUC) for OL but higher AUC for HT metabolites. ${ }^{54}$

The most comprehensive study regarding the identification of metabolites in human urine of most of the EVOOP (i.e. secoiridoids, flavanoids and phenolic alcohols) was reported by García-Villalba et al. ${ }^{55}$ These authors were able to achieve the tentative identification of 60 metabolites. Phenolic compounds were subjected to various phase I and phase II reactions, mainly methylation and glucuronidation. For instance, the largest number of metabolites was produced from HT, OL aglycone and oleocanthal, indicating significant post-absorption metabolism of these compounds. Conversely, the lowest number of metabolites came from TYR, luteolin, apigenin, pinoresinol and acetoxypinoresinol, suggesting that these compounds may have been excreted in faeces, destroyed in the gastrointestinal tract, excreted through another metabolic pathway or poorly absorbed. ${ }^{55}$ A recent paper by De la Torre et al. further confirmed the presence of HT and its major methylated metabolite, 3-O-methyl-hydroxytyrosol or HVAlc, in urine following EVOO consumption in high-risk CVD subjects, where the HVAlc concentration was predictive of CVD. ${ }^{56}$

In the case of poorly absorbed phenolic compounds, it has been suggested that these components may exert a local protective action in the large intestine, and this assumption is supported by research demonstrating, for instance, the free radical scavenging capacity of EVOOP in both the faecal matrix and intestinal epithelial cells. ${ }^{19}$

\section{Interaction with the microbiota}

EVOOP can likely influence the gut microbial balance since, as reviewed in the previous paragraph, most of them are not completely absorbed into the upper parts of the gastrointestinal tract and reach the colon, where the different microbial species that inhabit the intestine reach the highest concentration. ${ }^{57}$ The complex interaction between dietary polyphenols and the microbiota has been extensively studied, being recognized as one of the factors contributing to the beneficial effect 
of polyphenol consumption, although the mechanisms are still poorly understood.

Colon bacteria substantially contribute to the biotransformation of the polyphenols, breaking down unabsorbed compounds into a wide range of metabolites, which may be absorbed or excreted. Bacteria may also further modify enterocyte-derived metabolites. ${ }^{58}$ On the other hand, dietary polyphenols and their metabolites may strongly influence the microbiota composition, inhibiting the growth of harmful bacteria and exerting prebiotic-like effects towards beneficial bacteria, as nicely reviewed by Cardona $e t ~ a l .{ }^{58}$

However, studies specifically regarding the impact of the dietary intake of olives or EVOO polyphenols on the microbiota are scarce. One of the first studies on the biotransformation of ingested EVOOP by colonic microflora was the in vitro study conducted by Corona et al. ${ }^{28}$ cited above. The authors, using human fecal microbiota and a perfused rat intestinal model, demonstrated that these phenolic compounds undergo extensive metabolisation in the passage through the gastrointestinal tract and are mainly absorbed as simple phenols in the small intestine. However, OL reaches the large intestine as an unmodified compound and it is rapidly degraded in this site by the microflora to yield mainly HT. Using the same in vitro experimental model, Mosele et al. ${ }^{59}$ reported HT as the main product of OL microbial metabolisation, together with a pool of phenolic acids resulting from further metabolisation. HT, HT acetate and TYR, tested as individual phenols, also produced phenolic acids, such as phenylacetic acid, phenylpropionic acid and their hydroxylated derivatives.

A subsequent study determined in rat feces, after the oral administration of OL, the presence of the parent compound together with other metabolites, identified as HT, elenolic acid and HVA. ${ }^{60}$ In human fecal samples, obtained before and after the sustained intake of a phenol-enriched olive oil, free HT, phenylacetic acid, 2-(4'-hydroxyphenyl)acetic acid, 2-(3'-hydroxyphenyl)-acetic acid, and 3-(4'-hydroxyphenyl)-propionic acid were detected; neither OL nor HVA was present in human feces, probably because of the differences in the gut metabolic responses between rats and humans. ${ }^{59}$

Microbial-derived phenolic acids have been reported to exert a significant biological activity at the local and systemic level; ${ }^{61}$ phenylacetic and phenylpropionic acids, together with their variously hydroxylated derivatives, are among the predominant structures in fecal water ${ }^{62}$ and have shown to inhibit platelet aggregation ${ }^{63}$ and the growth of intestinal pathogenic bacteria. ${ }^{64}$

OL is likely to be preferentially degraded in vivo by lactic acid bacteria, such as Lactobacillus species, and Bifidobacterium species, ${ }^{65}$ which are involved in developing the spontaneous or started lactic fermentation of table olives but also contribute, as probiotic bacteria, to maintain or improve the microbial balance in the gut. ${ }^{66}$ Thanks to the $\beta$-glucosidase and esterase activity, ${ }^{67}$ L. plantarum, which is also found as a natural inhabitant of the human gastrointestinal tract, is the most effective bacteria converting OL into $\mathrm{HT}^{65,68}$ and it is also able to metabolize some phenolic acids such as protocatechuic acid, ${ }^{69}$ and ferulic, gallic and coumaric acids through inducible decarboxylase and reductase enzymes (ref. 70 and references therein). Thus, OL possesses prebiotic properties, as Lactobacillus and Bifidobacterium strains may utilize it as a carbon source, but others such as Clostridium and E. coli cannot. ${ }^{28}$ Actually, it is assumed that EVOOP might influence the composition of the microbiota also inhibiting the growth of pathogenic bacteria. The antimicrobial activity of phenolic compounds from Olea europaea has been extensively studied since the early 1970 s, although, depending on the experimental conditions, the results have been contrasting. HT, for example, has been shown to inhibit $E$. coli growth, ${ }^{71}$ although the culture media and the type of strain remarkably affected the bacterial susceptibility to HT. ${ }^{72}$ HT also exhibited a significant antimicrobial activity against selected Enterobacter species. ${ }^{73}$ Similarly, OL was effective in E. coli growth inhibition. ${ }^{74}$ In general, several experimental trials showed OL and HT to be the best inhibitors of several gastrointestinal pathogens, as reported in the recent review of Thielmann et al. ${ }^{75}$ However, this great amount of data arises from in vitro experiments that do not mimic the in vivo conditions. To the best of our knowledge, there are only two recent reports by MartinPelaez et $a l .^{76,77}$ and one from Conterno et $a .^{78}$ on the modulation of the microbiota by EVOOP in humans. Martin-Pelaez's studies arise from the VOHF study, a randomized, controlled, double-blind, crossover clinical trial with hypercholesterolemic subjects. $^{79}$ In a subsample of 12 hypercholesterolemic adults, ${ }^{76}$ changes in faecal microbial populations were evaluated following the sustained consumption of EVOOP, alone or in combination with thyme polyphenols; the study reported a slight HT modification in the microbial composition following EVOOP intake, depending on the dosage, as confirmed by a parallel study in another subsample of 10 subjects. ${ }^{77} \mathrm{~A}$ significant increase of Bifidobacterium group numbers was detected instead, when polyphenols from olive oil and thyme were ingested in combination. ${ }^{76}$ Among the microbial phenolic metabolites, dihydroxyphenyl and hydroxyphenyl acetic acid, and a significant amount of protocatechuic acid and HT were detected in faeces after dietary interventions with polyphenols. The ingestion of a mixture of olive oil and thyme polyphenols exerted a cardio-protective effect in hypercholesterolemic subjects, mediated by the specific growth stimulation of Bifidobacterium, together with the increases in microbial phenolic metabolites with antioxidant activities such as protocatechuic acid and $\mathrm{HT}^{76}{ }^{7}$ Conterno et al. reported small changes within the composition of the gut microbiota, showing a small increase in Bifidobacterium, and an up-regulation of microbial polyphenol biotransformation in the intestine, following the ingestion of olive pomace extract-enriched biscuits. ${ }^{78}$

Although the complex interrelation between EVOOP and the human microbiota is still far from being exhaustively investigated, the data collected so far clearly suggest a concentration dependent impact of phenolic compounds and metabolites on bacterial growth and on the associated metabolic consequences at the local and systemic level. 


\section{Antioxidant and anti-inflammatory effect at the intestinal level}

Dietary polyphenols have been claimed to exert both a protective and therapeutic effect in the management of gastrointestinal disorders, mainly those strictly linked to oxidative stress and chronic inflammation, such as IBD. Being particularly concentrated in the intestinal tract, dietary polyphenols, now undoubtedly associated with scientifically validated antioxidant and anti-inflammatory properties, may act locally, reducing oxidative stress and inflammatory response. ${ }^{2,80}$

\subsection{Antioxidant effect}

The gut lumen is likely to be the only site where EVOOP, together with their active metabolites, may reach a concentration high enough to enable them to act as direct antioxidants, scavenging ROS; once absorbed, they may also modulate the expression of genes linked to antioxidant cellular defenses via molecular targets. The phenolic fraction of EVOO has been shown to protect intestinal Caco-2 cells against the alteration of cellular redox status and oxidative damage to the membrane lipid fraction, due to the pro-oxidant action of oxidized lipids and this effect has been correlated to the activity of the most abundant phenolic compounds present in the tested fraction, HT, TYR and OL. ${ }^{81}$ As reviewed in the first paragraph, HT, TYR and OL, together with their metabolites, are the major phenols found at the intestinal level, following ingestion of EVOO, and, due to their high local concentrations, they might exert a relevant antioxidant effect. HT has been recognized as the most efficient free radical scavenger and radical chain breaker, and its catecholic structure is also able to prevent reactive species formation through metal chelation features. ${ }^{82,83}$ It has been shown to protect Caco-2 cells against oxidative injury, ${ }^{84-86}$ because of its scavenging properties, and its major metabolites, sulfates and glucuronides, showed an efficiency in protecting Caco-2 cells, ${ }^{87}$ as well as renal cells ${ }^{88}$ and erythrocytes ${ }^{89}$ comparable to or even better than that of the parent compound. TYR has also been shown to be effective in protecting Caco-2 cells against the cytostatic and cytotoxic effects produced by oxidized $\mathrm{LDL}^{90}$ and to possess scavenging effects on peroxyl radicals, ${ }^{84,91} \mathrm{O}_{2}^{-}$(ref. 92) and $\mathrm{ONOO}^{-93}$ Although there are no studies specifically regarding the intestinal compartment, trials in animal models and cell cultures demonstrated that HT is able to increase the endogenous defense system, through the modulation of related gene expression.

In human HepG2 cells HT enhanced the expression and the activity of the glutathione related enzymes, glutathione peroxidase (GPx), glutathione reductase (GR) and glutathione $S$-transferase (GST). ${ }^{94}$ The modulating activity of HT on the glutathione antioxidant network has been also demonstrated in the adipose tissue of mice fed an HT-supplemented diet ${ }^{95}$ and in the liver of obese mice after 17 weeks of supplementation. ${ }^{96} \mathrm{HT}$ has been shown to be a potent inducer of phase II detoxifying enzymes in retinal pigment epithelial cells ${ }^{97}$ and to increase the expression and activity of SOD and CAT in rats fed a cholesterol-rich diet. ${ }^{98}$ The effect of HT on the cellular antioxidant enzymes has been linked to its ability to increase the translocation of Nrf2 $2^{94,97}$ to the nucleus, thus promoting the expression of genes related to the antioxidant defense system and contributing to the protection of cells against oxidative stress. However, this hypothesis has never been proven in humans; indeed, a pilot study on humans demonstrated that HT administration did not significantly modify phase II enzyme expression in peripheral blood mononuclear cells. ${ }^{99}$

Recent studies showed the ability of TYR and its sulfate metabolite to induce the GPx activity in Caco-2 cells $^{87}$ and, together with its glucuronide metabolite, to restore the GSH level and related antioxidant enzymes in TNF- $\alpha$ treated human endothelial cells, ${ }^{100}$ as previously demonstrated in macrophages, where TYR preserved cellular antioxidant defenses against the pro-oxidant effect of oxidized LDL. ${ }^{101}$ In a mouse model of lipopolysaccharide (LPS)-induced acute lung injury, TYR pretreatment attenuated the inflammatory response and improved the expression of the antioxidant enzymes, through the activation of Nrf2. ${ }^{102}$

OL possesses well-documented pharmacological properties, including a potent antioxidant activity mainly due to the presence of hydroxyl groups in its chemical structure. Its free radical scavenging and metal-chelating activities enable OL to inhibit the production of a wide range of ROS and RNS in in vitro cell-free systems, as well as in cultured cells, as reported in Hassen et al.'s extensive review. ${ }^{103}$ There is also evidence for the stimulatory effect of $\mathrm{OL}$ on the expression of the intracellular antioxidant enzymes in free endothelial progenitor cells, via the activation of Nrf2, ${ }^{104}$ and in normal human liver cells. ${ }^{105}$ In vivo data confirm the ability of OL to increase the level and activities of enzymatic antioxidants in rats fed a cholesterol rich diet, ${ }^{106}$ in acute arsenic exposed rats, ${ }^{107}$ in the hypothalamus of hypertensive rats, ${ }^{108}$ and in the substantia nigra of aged rats ${ }^{109}$ and to enhance the level of non-enzymatic antioxidants such as glutathione, $\alpha$-tocopherol, ascorbic acid and $\beta$-carotene in alloxan-diabetic rabbits. ${ }^{110}$

\subsection{Anti-inflammatory effect}

A large body of studies carried out in cell cultures, animal models and humans provides solid evidence that EVOOP are able to inhibit the inflammatory process, through the modulation of different signaling pathways regulating immune cell response, activation of pro-inflammatory enzymes and release of inflammatory mediators. ${ }^{111}$

There are few studies focusing on the anti-inflammatory action of EVOOP at the intestinal level. In cultured Caco-2 cells stimulated with LPS or IL-1 $\beta$, EVOOP are able to regulate IL-8 expression by transcriptional or posttranscriptional mechanisms, depending on the stage of inflammation. ${ }^{112}$ We recently demonstrated that EVOOP may also counteract oxysterol-induced redox imbalance and pro-inflammatory response in Caco-2 cells, inhibiting cytokines and NO release, through the modulation of the MAPK-NF-KB pathway. ${ }^{113}$

Studies in animal models show that an EVOO diet enriched with phenolic compounds mitigates the severity of DSS-induced 
colitis in mice, attenuating the clinical and histological signs of damage of colonic segments, suppressing oxidative events and inhibiting pro-inflammatory protein expression. ${ }^{114-116}$

The anti-inflammatory activity of the phenolic fraction is likely to be dependent on the active constituents OL, HT and oleocanthal, whose anti-inflammatory effect has been clearly demonstrated in vitro. In the same mice model of DSS-induced colitis, oral administration of OL attenuated the extent and severity of acute colitis, reducing pro-inflammatory cytokine, IL-1 $\beta$, IL-6, TNF- $\alpha$ and NO production and enhancing antiinflammatory cytokine levels, IL-10, in the colonic tissue. The molecular mechanism of its protective action seems at least in part linked to the down-regulation of COX-2 and iNOS protein gene expression and to the up-regulation of annexin A1, which may mediate the suppression of p38 MAPK phosphorylation and NF- $\kappa \mathrm{B}$ translocation to the nucleus. ${ }^{116,117}$ A subsequent investigation by the same group confirmed the ability of OL to modulate intestinal immune response in a DSS acute model, inhibiting Th17 response and the release of Th17-related cytokines, and, down-regulating inflammatory mediators, to inhibit the development of the connected colorectal cancer. ${ }^{118}$

A recent study conducted in colonic biopsies obtained from patients with ulcerative colitis demonstrated the ability of OL to ameliorate the inflammatory damage and reduce the infiltration of CD3, CD4, and CD20 cells, while increasing CD68 numbers. In the colonic biopsies treated with LPS and OL the expression of COX-2 and IL-17 was significantly lower compared with those treated with LPS alone. ${ }^{119}$

HT also demonstrated an anti-inflammatory effect in vivo, when locally applied in TNBS-induced colitic rats, ${ }^{120}$ and when administered within HT supplemented EVOO diet to DSSinduced colitic mice. This anti-inflammatory effect has been related to the ability to modulate cytokine secretion and to reduce COX-2 and iNOS expression in colonic mucosa, by down-regulating the p38 MAPK pathway. ${ }^{121}$ These observations agree with the study of Corona et al. ${ }^{122}$ in Caco- 2 cells which demonstrates that the inhibition of p38 significantly reduces COX-2 expression.

A significant beneficial effect in chronic DSS-induced colitis was also exerted by HT acetate, sharing the same mechanism of action as HT. ${ }^{123}$ There is strong evidence in vitro that oleocanthal also is an effective anti-inflammatory agent. In fact, it can efficiently inhibit COX-2 enzyme expression and activity, which is implicated in the pathogenesis of several cancers. ${ }^{124}$

The findings of these few studies suggest that EVOOP have the potential to exert anti-inflammatory effects in the human gastrointestinal mucosa; however, no human studies, to date, have specifically dealt with this issue.

\section{Anti-carcinogenic effect at the intestinal level}

Over the past few decades, epidemiological studies have indicated an inverse correlation between EVOO consumption and the incidence of different types of cancers, although the scientific evidence in support of this correlation is still limited. ${ }^{125}$ It has been shown that the Mediterranean diet and EVOO seem to be protective against colon cancer. ${ }^{126,127}$ A systematic review and meta-analysis analyzed 19 case-control studies (13 800 cancer patients and 23340 controls) and found that high olive oil consumption was associated with lower odds of having any type of cancer. ${ }^{128}$ Moreover, high olive oil consumption was associated with lower odds of developing breast cancer $(\log \mathrm{OR}=$ $-0.45,95 \%$ CI -0.78 to -0.12 ), and a cancer of the digestive system $(\log \mathrm{OR}=-0.36,95 \% \mathrm{CI}-0.50$ to -0.21 ), compared with the lowest intake. ${ }^{128}$ In addition, another systematic review and meta-analysis included 25 studies, and concluded that high olive oil consumption decreased the risk of upper digestive and respiratory tract neoplasms, and breast and, possibly, colorectal and other cancer sites. ${ }^{125}$ More recently, a systematic review reported the association between EVOOP and other Mediterranean diet components with a reduction of colorectal cancer initiation, promotion and progression. ${ }^{129}$ Several nutrients play a significant role in colorectal cancer development, and the importance of monounsaturated fatty acids has been highlighted. ${ }^{130}$

In addition, EVOOP, including phenolic alcohols, lignans and secoiridoids, are thought to be, in part, responsible for EVOO reported anti-carcinogenic effects. ${ }^{131}$ EVOOP have been shown to influence carcinogenesis and tumor development at various levels: ${ }^{132-134}$ by exerting antioxidant activities, ${ }^{135,136}$ by modulating detoxification enzyme systems, ${ }^{137}$ and the immune system, ${ }^{138}$ by reacting with activated carcinogens and mutagens, ${ }^{139,140}$ and by exerting actions on proteins controlling cell cycle progression, ${ }^{122,141,142}$ and gene expression. ${ }^{143,144}$

The ability of EVOO to inhibit colon cancer development has been demonstrated in large intestinal cancer cell models, ${ }^{122,144,145}$ in animals ${ }^{140,146}$ and in humans. ${ }^{131,147}$ In experimental models, olive oil consumption has been shown to prevent benzo $(a)$ pyrene $[\mathrm{B}(a) \mathrm{P}]$-induced colon carcinogenesis in Apc(Min) mice, ${ }^{140}$ reduce the incidence of aberrant crypt foci in azoxymethane-treated rats ${ }^{146}$ and dimethyl-benz (a)anthracene-induced mammary carcinogenesis, ${ }^{148}$ and has been shown to induce significant levels of apoptosis in large intestinal cancer cells. ${ }^{136,145}$ In animal models, n9 fatty acids present in olive oil have been able to prevent the development of aberrant crypt foci and colon carcinomas. ${ }^{146}$ Thus, EVOOP have also been shown to play an important role, due to their ability to inhibit the initiation, promotion and metastasis of the carcinogenetic process in human colon adenocarcinoma cells. ${ }^{149,150}$ Furthermore, EVOO has been shown to down-regulate the expression of $\mathrm{COX}-2$ and $\mathrm{Bcl}-2$ proteins that have a crucial role in colorectal carcinogenesis. ${ }^{145}$

A study conducted using different colon cancer cell lines (p53 proficient, mutant and knocked out) demonstrated that a pinoresinol-rich olive oil extract was capable of reducing cancer cell viability (particularly in p53-proficient cells), inducing apoptosis, inducing a G2/M cell cycle block and causing the up-regulation of ATM and a parallel decrease of cyclin $\mathrm{B} / \mathrm{cdc} 2{ }^{151}$ Similar experiments conducted with purified pinoresi- 
Table 1 Overview of EVOOP actions at the intestinal level

\begin{tabular}{|c|c|}
\hline Compound & Experimental system \\
\hline \multicolumn{2}{|l|}{ Interaction with microbiota } \\
\hline OL, HT, TYR & $\begin{array}{l}\text { In vitro batch colonic fermentation/perfused } \\
\text { rat intestinal model }\end{array}$ \\
\hline $\begin{array}{l}\text { TYR, HT, HT acetate and OL/ } \\
\text { phenol-enriched OO }\end{array}$ & $\begin{array}{l}\text { In vitro batch colonic fermentation/human } \\
\text { intervention study }\end{array}$ \\
\hline $\mathrm{OL}$ & Oral administration in rats \\
\hline HT, TYR & Broth dilution \\
\hline $\mathrm{HT}$ & Broth dilution \\
\hline HT & Agar plates \\
\hline OL, HT/phenolic extract & Broth dilution \\
\hline $\begin{array}{l}\text { Phenol-enriched OO/phenol } \\
\text { and thyme phenol-enriched } \\
\text { OO }\end{array}$ & Double-blind, crossover human trial \\
\hline $\begin{array}{l}\text { Olive pomace enriched } \\
\text { biscuits }\end{array}$ & $\begin{array}{l}\text { Double-blind, parallel dietary intervention ir } \\
\text { human subjects }\end{array}$ \\
\hline \multicolumn{2}{|l|}{ Antioxidant effect } \\
\hline HT, TYR, homovanillic alcohol & $\begin{array}{l}\text { TBH treated human colon adenocarcinoma } \\
\text { cells (Caco-2) }\end{array}$ \\
\hline HT & $\begin{array}{l}\mathrm{H}_{2} \mathrm{O}_{2} \text { or xanthine oxidase/xanthine treated } \\
\text { Caco-2 cells }\end{array}$ \\
\hline HT & Acrylamide treated Caco-2 cells \\
\hline $\begin{array}{l}\text { HT, TYR and sulfate } \\
\text { metabolites }\end{array}$ & Oxidized cholesterol treated Caco-2 cells \\
\hline TYR & Oxidized LDL treated Caco- 2 cells \\
\hline Phenolic extract & Oxysterol treated Caco-2 cells \\
\hline
\end{tabular}

\section{Anti-inflammatory effect}

Phenolic extract

Phenolic extract

Phenol-enriched EVOO

EVOO unsaponifiable fraction

OL

OL

OL

OL

HT

HT-enriched EVOO

HT acetate

\section{Anti-carcinogenic effect}

Phenolic extract

HT

HT vitro batch colonic fermentation/perfused

intervention study

Agar plates

Broth dilution

Oxysterol treated Caco-2 cells

LPS or IL-1 $\beta$ treated Caco- 2 cells

Oxysterol treated Caco-2 cells

DSS-induced chronic colitis in mice

DSS-induced acute colitis in mice

DSS-induced acute colitis in mice

DSS-induced chronic colitis in mice

DSS-induced acute colitis in mice

LPS treated colonic biopsies from UC patients

TNBS-induced colitis in rats

DSS-induced chronic colitis in mice

DSS-induced acute colitis in mice

Caco-2 cells

Caco-2 cells
Adenocarcinoma cells (DLD1 cells)
Mechanism

Ref.

Increase of bioactive phenolic metabolites

28

Increase of bioactive phenolic metabolites in faeces

Increase of bioactive phenolic metabolites in faeces

Growth inhibition of E. coli (ATCC no. 25922)

Growth inhibition of E. coli (CECT 533, 4972, and

679 grown in LB and $E$. coli 4972 grown in ISO)

Growth inhibition of E. coli, Enterobacter and

Enterococcus species

Growth inhibition of E. coli (C7085L)

Increase of Bifidobacterium

Increase of bioactive phenolic metabolites in faeces

Increase of Bifidobacterium

Inhibition of the oxidative modification of the membrane lipid fraction

Inhibition of lipid peroxidation and monolayer

permeability changes

Prevention of ROS overproduction

Inhibition of ROS and MDA production and GSH

depletion

Inhibition of morphological and functional alterations

Reduction of ROS production and GSH depletion

Prevention of IL-8 expression and secretion, regulation of IL-8 mRNA transcription and stability Inhibition of IL-6, IL-8 and NO release, modulation of the MAPK-NF- $\mathrm{kB}$ pathway

Attenuated damage of colonic segments, PPAR $\gamma$ upregulation, NF-KB, MAPK and downstream inflammatory cascade inhibition

Attenuated damage of colonic segments, decreased

MCP-1 and TNF- $\alpha$ levels, iNOS and COX-2

overexpression and p38 MAPK activation

Reduction of neutrophil infiltration, NO, IL-1 $\beta$, IL-6, and TNF- $\alpha$ production, iNOS, COX-2, and MMP-9 expression

Attenuated colon damage, reduction of COX-2 and

iNOS expression and IL-1 $\beta$ and IL- 6 release; increase of IL-10

Inhibition of Th17 response and Th17-related cytokine release

Reduced expression of COX-2 and IL-17 and infiltration of CD3, CD4 and CD20 cells

Reduced inflammatory infiltration

Attenuated colon damage, reduced TNF- $\alpha, \mathrm{COX}-2$ and

iNOS expression, downregulation of p38 MAPK; increase of IL10

Improved histological damage, reduction of COX-2 and iNOS expression, inhibition of JNK MAPK and NF-kB

Inhibition of cell proliferation, induction of $\mathrm{G} 2 / \mathrm{M}$ phase cell cycle block, inhibition of p38 and CREB activation, reduction in COX-2 expression

ROS generation, apoptotic cell death, mitochondrial dysfunction, phosphoinositide 3-kinase/Akt pathway activation, FOXO3a phosphorylation, FOXO3a's target gene downregulation

Inhibition of cell proliferation, induction of $\mathrm{G} 2 / \mathrm{M}$ phase cell cycle block, inhibition of ERK1/2 activation, reduction of cyclin D1 expression 
Table 1 (Contd.)

\begin{tabular}{|c|c|c|c|}
\hline Compound & Experimental system & Mechanism & Ref. \\
\hline Phenolic extract & $\begin{array}{l}\text { Colon cancer cells (HT-29), intestinal barrier } \\
\text { function (Caco-2 cell monolayers), matrigel } \\
\text { invasion assay (HT115 cells) }\end{array}$ & $\begin{array}{l}\text { Reduction of DNA damage (HT-29), improved barrier } \\
\text { function (Caco-2), inhibition of HT115 invasion, } \\
\text { inhibition of HT115 cell attachment }\end{array}$ & 149 \\
\hline $\begin{array}{l}\text { Phenolic extract, HT, TYR, } \\
\text { pinoresinol, caffeic acid }\end{array}$ & Matrigel invasion assay (HT115 cells) & $\begin{array}{l}\text { Anti-invasive effects, no cytotoxicity observed, no effects } \\
\text { on cell attachment }\end{array}$ & 150 \\
\hline $\begin{array}{l}\text { Pinoresinol-rich phenolic } \\
\text { extract, oleocanthal-rich } \\
\text { phenolic extract }\end{array}$ & $\begin{array}{l}\text { p53 proficient (RKO and HCT116), and p53 } \\
\text { knocked out (SW480 and HCT116 p53-/-) cell } \\
\text { lines }\end{array}$ & $\begin{array}{l}\text { Reduction of cell viability, increased apoptosis, cell } \\
\text { cycle arrest at } \mathrm{G}(2) / \mathrm{M} \text {, up-regulation of the ATM } \\
\text { signalling pathway, decrease of cyclin B/cdc2 }\end{array}$ & 151 \\
\hline HT & HT-29 & Inhibition of cell proliferation & 156 \\
\hline HT & HT-29 & $\begin{array}{l}\text { Induction of cell growth arrest, induction of apoptosis, } \\
\text { prolonged stress of the endoplasmic reticulum (ER), } \\
\text { activation of UPR, overexpression of CHOP/GADD153, } \\
\text { activation of JNK, modulation of Akt/PKB, inhibition of } \\
\text { TNF } \alpha \text {-induced NF-KB }\end{array}$ & 157 \\
\hline
\end{tabular}

nol resulted in similar effects, although higher concentrations were required, indicating a possible synergistic effect between pinoresinol and other polyphenols in EVOO. ${ }^{151}$

The cellular mechanism by which EVOOP exert anticancer effects can also be linked to the modulation of MAPK kinases and COX-2. ${ }^{122}$ COX-2 is over-expressed in colorectal cancer, and its over-expression has a strong association with colorectal neoplasia, by promoting cell survival, cell growth, migration, invasion and angiogenesis. ${ }^{152}$ An efficient inhibitor of COX-2, oleocanthal, repressed cell viability and induced apoptosis in human colon carcinoma HT-29 cells, via AMPK activation and COX-2 suppression, ${ }^{153}$ and it has also been proven to reduce proliferation and migration in different cancer cells, deactivating the activity of various mediators in addition to COX-2, which result in tumorogenesis. ${ }^{124}$

The MAPK signaling pathway has long been viewed as an attractive pathway for anticancer therapies, based on its central role in regulating the growth and survival of cells from a broad spectrum of human cancers, ${ }^{154}$ and it also modulates the transcriptional and post-transcriptional activation of COX-2. ${ }^{155}$

An EVOO phenolic extract has been shown to exert a strong inhibitory effect on the growth of colon adenocarcinoma cells through the inhibition of p38/CREB signaling, a decrease in COX-2 expression and the stimulation of a G2/M phase cell cycle block. ${ }^{122}$ In contrast, HT exerts its anti-proliferative effects via its ability to strongly inhibit ERK1/2 phosphorylation and downstream cyclin D1 expression. ${ }^{142}$ These findings are of particular relevance due to the high colonic bioavailability of HT compared to the other EVOOP and may help explain the inverse link between colon cancer and EVOO consumption.

Furthermore, HT inhibits colon cancer cell proliferation ${ }^{156}$ and induces cancer cell apoptosis ${ }^{157}$ through a mechanism of action linked to a prolonged stress of the endoplasmic reticulum (activation of unfolded proteins) and over-expression of pro-apoptotic factors, such as Ser/Thr phosphatase 2A, a key protein involved in the induction of apoptosis in colon cancer cells. ${ }^{157}$ TYR, on the other hand, has been found to reverse a number of effects induced by oxidized lipids, including ROS overproduction, GSH depletion, the impairment in antioxidant enzyme activity and the increase in the expression of p66Shc protein. ${ }^{101,158,159}$ All of these findings suggest that the ability of EVOOP as intestinal anti-cancer agents should be reappraised, as it is clear that their actions on the process of carcinogenesis are manifold and involve more than a simple antioxidant effect.

\section{Conclusions}

A large body of evidence suggests the potential for EVOOP to promote beneficial health effects in the prevention and amelioration of several chronic diseases, mainly cardiovascular disease, neurodegenerative disorders and cancer, as recently outlined by Visioli et al., who critically summarized the main reported findings on the effects of EVOO consumption on human health, discussed in the last International Olive Council Conference. ${ }^{160}$ Studies on the absorption and metabolization of EVOOP show that some complex polyphenols reach the intestine, where they may be directly absorbed or metabolized during absorption, while others undergo an extensive gastrointestinal biotransformation. Therefore, a significant amount of bioactive compounds, mainly simple phenols and metabolites, will be present in the small and large intestines, concentrating at this site.

Considering that the dietary intake of EVOOP in the Mediterranean area has been estimated to be around $9 \mathrm{mg}$, based on a daily consumption of $25-50 \mathrm{ml}$ of EVOO, ${ }^{19}$ EVOOP may significantly contribute to preserve intestinal epithelium homeostasis. As suggested by the few studies summarized in this review (Table 1), EVOOP may help to counteract oxidative 
stress and can modulate intestinal inflammation, gut microbiota and immune response, thus helping to prevent the onset or delay the progression of inflammatory/degenerative diseases. Although more studies are necessary to validate the important role of EVOOP in the maintenance of intestinal homeostasis, the regular consumption of EVOO should be highly promoted also in view of their possible role in preventing intestinal diseases.

\section{Abbreviations}

EVOO Extra virgin olive oil

EVOOP Extra virgin olive oil polyphenols

HT Hydroxytyrosol

TYR Tyrosol

OL Oleuropein

HVA Homovanillic acid

HVAlc Homovanillyl alcohol

\section{Conflicts of interest}

No conflicts of interest.

\section{References}

1 J. A. Uranga, V. Lopez-Miranda, F. Lombo and R. Abalo, Food, nutrients and nutraceuticals affecting the course of inflammatory bowel disease, Pharmacol. Rep., 2016, 68, 816-826.

2 A. Kaulmann and T. Bohn, Bioactivity of Polyphenols: Preventive and Adjuvant Strategies toward Reducing Inflammatory Bowel Diseases-Promises, Perspectives, and Pitfalls, Oxid. Med. Cell. Longevity, 2016, 2016, 9346470.

3 A. Scalbert and G. Williamson, Dietary intake and bioavailability of polyphenols, J. Nutr., 2000, 130, 2073S2085S.

4 B. Halliwell, J. Rafter and A. Jenner, Health promotion by flavonoids, tocopherols, tocotrienols, and other phenols: direct or indirect effects? Antioxidant or not?, Am. J. Clin. Nutr., 2005, 81, 268S-276S.

5 L. Parkinson and S. Cicerale, The Health Benefiting Mechanisms of Virgin Olive Oil Phenolic Compounds, Molecules, 2016, 21, 1734.

6 R. Estruch, E. Ros, J. Salas-Salvado, M. I. Covas, D. Corella, F. Aros, E. Gomez-Gracia, V. Ruiz-Gutierrez, M. Fiol, J. Lapetra, R. M. Lamuela-Raventos, L. SerraMajem, X. Pinto, J. Basora, M. A. Munoz, J. V. Sorli, J. A. Martinez and M. A. Martinez-Gonzalez, Primary prevention of cardiovascular disease with a Mediterranean diet, N. Engl. J. Med., 2013, 368, 1279-1290.

7 R. Casas, R. Estruch and E. Sacanella, The Protective Effects of Extra Virgin Olive Oil on Immune-mediated
Inflammatory Responses, Endocr., Metab. Immune Disord.: Drug Targets, 2018, 18, 23-35.

8 E. Bernardini and F. Visioli, High quality, good health: The case for olive oil, Eur. J. Lipid Sci. Technol., 2017, 119, 1500505.

9 M. I. Covas, M. Fito and R. De la Torre, in Olive and Olive Oil Bioactive Constituents, AOCS Press, 2015, pp. 31-52.

10 L. Cerretani, T. Galllina Toschi and A. Bendini, in Functional Plant Science and Biotechnology, Global Science Books, 2009.

11 T. Gallina-Toschi, L. Cerretani, A. Bendini, M. BonoliCarbognin and G. Lercker, Oxidative stability and phenolic content of virgin olive oil: an analytical approach by traditional and high resolution techniques, J. Sep. Sci., 2005, 28, 859-870.

12 M. Saitta, F. Salvo, G. Di Bella, G. Dugo and G. La Torre, Minor compounds in the phenolic fraction of virgin olive oils, Food Chem., 2009, 112, 525-532.

13 V. Lavelli and L. Bondesan, Secoiridoids, tocopherols, and antioxidant activity of monovarietal extra virgin olive oils extracted from destoned fruits, J. Agric. Food Chem., 2005, 53, 1102-1107.

14 A. Cardeno, M. Sanchez-Hidalgo and C. Alarcon-de-laLastra, An up-date of olive oil phenols in inflammation and cancer: molecular mechanisms and clinical implications, Curr. Med. Chem., 2013, 20, 4758-4776.

15 A. Bianco, F. Coccioli, M. Guiso and C. Marra, The occurrence in olive oil of a new class of phenolic compounds: Hydroxy-isochromans, Food Chem. Toxicol., 2001, 77, 405411.

16 P. Rovellini and N. Cortesi, Liquid chromatography-mass spectrometry in the study of oleuropein and ligstroside aglycons in virgin olive oils: Aldehydic, dialdehydic forms and their oxidized products, Riv. Ital. Sostanze Grasse, 2002, 79, 1-14.

17 R. W. Owen, W. Mier, A. Giacosa, W. E. Hull, B. Spiegelhalder and H. Bartsch, Phenolic compounds and squalene in olive oils: the concentration and antioxidant potential of total phenols, simple phenols, secoiridoids, lignansand squalene, Food Chem. Toxicol., 2000, 38, 647-659.

18 M. Servili, R. Selvaggini, S. Esposto, A. Taticchi, G. Montedoro and G. Morozzi, Health and sensory properties of virgin olive oil hydrophilic phenols: agronomic and technological aspects of production that affect their occurrence in the oil, J. Chromatogr. A, 2004, 1054, 113127.

19 R. de la Torre, Bioavailability of olive oil phenolic compounds in humans, Inflammopharmacology, 2008, 16, 245247.

20 S. Cicerale, X. A. Conlan, A. J. Sinclair and R. S. Keast, Chemistry and health of olive oil phenolics, Crit. Rev. Food Sci. Nutr., 2009, 49, 218-236.

21 M. Gorzynik-Debicka, P. Przychodzen, F. Cappello, A. Kuban-Jankowska, A. Marino Gammazza, N. Knap, M. Wozniak and M. Gorska-Ponikowska, Potential Health 
Benefits of Olive Oil and Plant Polyphenols, Int. J. Mol. Sci., 2018, 19, 547.

22 S. Cicerale, L. Lucas and R. Keast, Biological activities of phenolic compounds present in virgin olive oil, Int. J. Mol. Sci., 2010, 11, 458-479.

23 G. Fregapane, A. Gomez-Rico, A. M. Inarejos and M. D. Salvador, Relevance of minor components stability in commercial olive oil quality during the market period, Eur. J. Lipid Sci. Technol., 2013, 115, 541-548.

24 O. S. Jolayemi, F. Tokatli and B. Ozen, Effects of malaxation temperature and harvest time on the chemical characteristics of olive oils, Food Chem., 2016, 211, 776783.

25 A. Soler, M. P. Romero, A. Macià, S. Saha, C. S. M. Furniss, P. A. Kroon and M. J. Motilva, Digestion stability and evaluation of the metabolism and transport of olive oil phenols in the human small-intestinal epithelial Caco-2/ TC7 cell line, Food Chem., 2010, 119, 704-714.

26 S. Cicerale, L. J. Lucas and R. S. Keast, Antimicrobial, antioxidant and anti-inflammatory phenolic activities in extra virgin olive oil, Curr. Opin. Biotechnol., 2012, 23, 129135.

27 J. Rodriguez-Morato, A. Boronat, A. Kotronoulas, M. Pujadas, A. Pastor, E. Olesti, C. Perez-Mana, O. Khymenets, M. Fito, M. Farre and R. de la Torre, Metabolic disposition and biological significance of simple phenols of dietary origin: hydroxytyrosol and tyrosol, Drug Metab. Rev., 2016, 48, 218-236.

28 G. Corona, X. Tzounis, M. Assunta Dessi, M. Deiana, E. S. Debnam, F. Visioli and J. P. Spencer, The fate of olive oil polyphenols in the gastrointestinal tract: implications of gastric and colonic microflora-dependent biotransformation, Free Radical Res., 2006, 40, 647-658.

29 J. Pinto, F. Paiva-Martins, G. Corona, E. S. Debnam, M. Jose Oruna-Concha, D. Vauzour, M. H. Gordon and J. P. Spencer, Absorption and metabolism of olive oil secoiridoids in the small intestine, Br. J. Nutr., 2011, 105, 1607-1618.

30 M. N. Vissers, P. L. Zock, A. J. Roodenburg, R. Leenen and M. B. Katan, Olive oil phenols are absorbed in humans, J. Nutr., 2002, 132, 409-417.

31 F. Visioli, C. Galli, E. Plasmati, S. Viappiani, A. Hernandez, C. Colombo and A. Sala, Olive phenol hydroxytyrosol prevents passive smoking-induced oxidative stress, Circulation, 2000, 102, 2169-2171.

32 E. Miro-Casas, M. Farre Albaladejo, M. I. Covas, J. O. Rodriguez, E. Menoyo Colomer, R. M. Lamuela Raventos and R. de la Torre, Capillary gas chromatography-mass spectrometry quantitative determination of hydroxytyrosol and tyrosol in human urine after olive oil intake, Anal. Biochem., 2001, 294, 63-72.

33 F. Visioli, D. Caruso, E. Plasmati, R. Patelli, N. Mulinacci, A. Romani, G. Galli and C. Galli, Hydroxytyrosol, as a component of olive mill waste water, is dose- dependently absorbed and increases the antioxidant capacity of rat plasma, Free Radical Res., 2001, 34, 301-305.
34 K. L. Tuck and P. J. Hayball, Major phenolic compounds in olive oil: metabolism and health effects, J. Nutr. Biochem., 2002, 13, 636-644.

35 T. Weinbrenner, M. Fito, M. Farre Albaladejo, G. T. Saez, P. Rijken, C. Tormos, S. Coolen, R. De La Torre and M. I. Covas, Bioavailability of phenolic compounds from olive oil and oxidative/antioxidant status at postprandial state in healthy humans, Drugs Exp. Clin. Res., 2004, 30, 207-212.

36 M. I. Covas, K. de la Torre, M. Farre-Albaladejo, J. Kaikkonen, M. Fito, C. Lopez-Sabater, M. A. PujadasBastardes, J. Joglar, T. Weinbrenner, R. M. LamuelaRaventos and R. de la Torre, Postprandial LDL phenolic content and LDL oxidation are modulated by olive oil phenolic compounds in humans, Free Radical Biol. Med., 2006, 40, 608-616.

37 L. Rubio, A. Macia, A. Castell-Auvi, M. Pinent, M. T. Blay, A. Ardevol, M. P. Romero and M. J. Motilva, Effect of the co-occurring olive oil and thyme extracts on the phenolic bioaccessibility and bioavailability assessed by in vitro digestion and cell models, Food Chem., 2014, 149, 277284.

38 E. Miro Casas, M. Farre Albadalejo, M. I. Covas Planells, M. Fito Colomer, R. M. Lamuela Raventos and R. de la Torre Fornell, Tyrosol bioavailability in humans after ingestion of virgin olive oil, Clin. Chem., 2001, 47, 341343.

39 E. Miro-Casas, M. I. Covas, M. Farre, M. Fito, J. Ortuno, T. Weinbrenner, P. Roset and R. de la Torre, Hydroxytyrosol disposition in humans, Clin. Chem., 2003, 49, 945-952.

40 E. Miro-Casas, M. I. Covas, M. Fito, M. Farre-Albadalejo, J. Marrugat and R. de la Torre, Tyrosol and hydroxytyrosol are absorbed from moderate and sustained doses of virgin olive oil in humans, Eur. J. Clin. Nutr., 2003, 57, 186-190.

41 C. Manna, P. Galletti, G. Maisto, V. Cucciolla, S. D’Angelo and V. Zappia, Transport mechanism and metabolism of olive oil hydroxytyrosol in Caco-2 cells, FEBS Lett., 2000, 470, 341-344.

42 R. Mateos, G. Pereira-Caro, S. Saha, R. Cert, M. RedondoHorcajo and L. Bravo, Acetylation of Hydroxytyrosol Enhances its Transport across Differentiated Caco-2 Cell Monolayers, Food Chem., 2011, 123, 865-872.

43 S. C. Edgecombe, G. L. Stretch and P. J. Hayball, Oleuropein, an antioxidant polyphenol from olive oil, is poorly absorbed from isolated perfused rat intestine, J. Nutr., 2000, 130, 2996-3002.

44 C. Manach, A. Scalbert, C. Morand, C. Remesy and L. Jimenez, Polyphenols: food sources and bioavailability, Am. J. Clin. Nutr., 2004, 79, 727-747.

45 D. Caruso, F. Visioli, R. Patelli, C. Galli and G. Galli, Urinary excretion of olive oil phenols and their metabolites in humans, Metabolism, 2001, 50, 1426-1428.

46 O. Khymenets, M. Farré, M. Pujadas, E. Ortiz, J. Joglar, M. I. Covas and R. de la Torre, Direct analysis of glucuro- 
nidated metabolites of main olive oil phenols in human urine after dietary consumption of virgin olive oil, Food Chem., 2011, 126, 306-314.

47 S. D’Angelo, C. Manna, V. Migliardi, O. Mazzoni, P. Morrica, G. Capasso, G. Pontoni, P. Galletti and V. Zappia, Pharmacokinetics and metabolism of hydroxytyrosol, a natural antioxidant from olive oil, Drug Metab. Dispos., 2001, 29, 1492-1498.

48 K. L. Tuck, M. P. Freeman, P. J. Hayball, G. L. Stretch and I. Stupans, The in vivo fate of hydroxytyrosol and tyrosol, antioxidant phenolic constituents of olive oil, after intravenous and oral dosing of labeled compounds to rats, J. Nutr., 2001, 131, 1993-1996.

49 F. Visioli, C. Galli, S. Grande, K. Colonnelli, C. Patelli, G. Galli and D. Caruso, Hydroxytyrosol excretion differs between rats and humans and depends on the vehicle of administration, J. Nutr., 2003, 133, 2612-2615.

50 L. Rubio, R. M. Valls, A. Macia, A. Pedret, M. Giralt, M. P. Romero, R. de la Torre, M. I. Covas, R. Sola and M. J. Motilva, Impact of olive oil phenolic concentration on human plasmatic phenolic metabolites, Food Chem., 2012, 135, 2922-2929.

51 M. Suarez, R. M. Valls, M. P. Romero, A. Macia, S. Fernandez, M. Giralt, R. Sola and M. J. Motilva, Bioavailability of phenols from a phenol-enriched olive oil, Br. J. Nutr., 2011, 106, 1691-1701.

52 O. Khymenets, M. C. Crespo, O. Dangles, N. Rakotomanomana, C. Andres-Lacueva and F. Visioli, Human hydroxytyrosol's absorption and excretion from a nutraceutical, J. Funct. Foods, 2016, 23, 278-282.

53 M. Suárez, M. P. Romero, A. Macia, R. M. Valls, S. Fernandez, R. Sola and M. J. Motilva, Improved method for identifying and quantifying olive oil phenolic compounds and their metabolites in human plasma by microelution solid-phase extraction plate and liquid chromatography-tandem mass spectrometry, J. Chromatogr. B: Anal. Technol. Biomed. Life Sci., 2009, 877, 4097-4106.

54 M. de Bock, E. B. Thorstensen, J. G. Derraik, H. V. Henderson, P. L. Hofman and W. S. Cutfield, Human absorption and metabolism of oleuropein and hydroxytyrosol ingested as olive (Olea europaea L.) leaf extract, Mol. Nutr. Food Res., 2013, 57, 2079-2085.

55 R. García-Villalba, A. Carrasco-Pancorbo, E. Nevedomskaya, O. A. Mayboroda, A. M. Deelder, A. Segura-Carretero and A. Fernandez-Gutierrez, Exploratory analysis of human urine by LC-ESI-TOF MS after high intake of olive oil: understanding the metabolism of polyphenols, Anal. Bioanal. Chem., 2010, 398, 463-475.

56 R. De la Torre, D. Corella, O. Castaner, M. A. MartinezGonzalez, J. Salas-Salvador, J. Vila, R. Estruch, J. V. Sorli, F. Aros, M. Fiol, E. Ros, L. Serra-Majem, X. Pinto, E. Gomez-Gracia, J. Lapetra, M. Ruiz-Canela, J. Basora, E. M. Asensio, M. I. Covas and M. Fito, Protective effect of homovanillyl alcohol on cardiovascular disease and total mortality: virgin olive oil, wine, and catechol-methylathion, Am. J. Clin. Nutr., 2017, 105, 1297-1304.
57 G. P. Donaldson, S. M. Lee and S. K. Mazmanian, Gut biogeography of the bacterial microbiota, Nat. Rev. Microbiol., 2016, 14, 20-32.

58 F. Cardona, C. Andres-Lacueva, S. Tulipani, F. J. Tinahones and M. I. Queipo-Ortuno, Benefits of polyphenols on gut microbiota and implications in human health, J. Nutr. Biochem., 2013, 24, 1415-1422.

59 J. I. Mosele, S. Martin-Pelaez, A. Macia, M. Farras, R. M. Valls, U. Catalan and M. J. Motilva, Faecal microbial metabolism of olive oil phenolic compounds: in vitro and in vivo approaches, Mol. Nutr. Food Res., 2014, 58, 1809-1819.

60 P. Lin, W. Qian, X. Wang, L. Cao, S. Li and T. Qian, The biotransformation of oleuropein in rats, Biomed. Chromatogr., 2013, 27, 1162-1167.

$61 \mathrm{~W}$. Russell and G. Duthie, Plant secondary metabolites and gut health: the case for phenolic acids, Proc. Nutr. Soc., 2011, 70, 389-396.

62 A. M. Jenner, J. Rafter and B. Halliwell, Human fecal water content of phenolics: The extent of colonic exposure to aromatic compounds, Free Radical Biol. Med., 2005, 38, 763-772.

63 A. R. Rechner and C. Kroner, Anthocyanins and colonic metabolites of dietary polyphenols inhibit platelet function, Thromb. Res., 2005, 116, 327-334.

64 C. Cueva, M. V. Moreno-Arribas, P. J. Martin-Alvarez, G. Bills, M. F. Vicente, A. Basilio, C. L. Rivas, T. Requena, J. M. Rodriguez and B. Bartolome, Antimicrobial activity of phenolic acids against commensal, probiotic and pathogenic bacteria, Res. Microbiol., 2010, 161, 372382.

65 M. M. Santos, C. Piccirillo, P. M. L. Castro, N. Kalogerakis and M. E. Pintado, Bioconversion of oleuropein to hydroxytyrosol by lactic acid bacteria, World J. Microbiol. Biotechnol., 2012, 28, 2435-2440.

66 M. Saarela, L. Lahteenmaki, R. Crittenden, S. Salminen and T. Mattila-Sandholm, Gut bacteria and health foods the European perspective, Int. J. Food Microbiol., 2002, 78, 99-117.

67 M. Avila, M. Hidalgo, C. Sanchez-Moreno, C. Pelaez, T. Requena and S. de Pascual-Teresa, Bioconversion of anthocyanin glycosides by Bifidobacteria and Lactobacillus, Food Res. Int., 2009, 42, 1453-1461.

68 V. Marsilio and B. Lanza, Characterisation of an oleuropein degrading strain of Lactobacillus plantarum. Combined effects of compounds present in olive fermenting brines (phenols, glucose and $\mathrm{NaCl}$ ) on bacterial activity, J. Sci. Food Agric., 1998, 76, 520-524.

69 J. M. Landete, J. A. Curiel, H. Rodriguez, B. de las Rivas and R. Munoz, Study of the inhibitory activity of phenolic compounds found in olive products and their degradation by Lactobacillus plantarum strains, Food Chem., 2008, 107, 320-326.

70 H. Rodriguez, J. A. Curiel, J. M. Landete, B. de las Rivas, F. L. de Felipe, C. Gomez-Cordoves, J. M. Mancheno and R. Munoz, Food phenolics and lactic acid bacteria, Int. J. Food Microbiol., 2009, 132, 79-90. 
71 A. Tafesh, N. Najami, J. Jadoun, F. Halahlih, H. Riepl and H. Azaizeh, Synergistic antibacterial effects of polyphenolic compounds from olive mill wastewater, Evid Based Complement Alternat. Med., 2011, 2011, 431021.

72 M. S. Medina-Martinez, P. Truchado, I. Castro-Ibanez and A. Allende, Antimicrobial activity of hydroxytyrosol: a current controversy, Biosci., Biotechnol., Biochem., 2016, 80, 801-810.

73 E. Medina, M. Brenes, C. Romero, A. Garcia and A. de Castro, Main antimicrobial compounds in table olives, J. Agric. Food Chem., 2007, 55, 9817-9823.

74 A. T. Serra, A. A. Matias, A. V. M. Nunes, M. C. Leitao, D. Brito, R. Bronze, S. Silva, A. Pires, M. T. Crespo, M. V. S. Romao and C. M. Duarte, In vitro evaluation of olive- and grape-based natural extracts as potential preservatives for food, Innovative Food Sci. Emerging Technol., 2008, 9, 311-319.

75 J. Thielmann, S. Kohnen and C. Hauser, Antimicrobial activity of Olea europaea Linne extracts and their applicability as natural food preservative agents, Int. J. Food Microbiol., 2017, 251, 48-66.

76 S. Martin-Pelaez, J. I. Mosele, N. Pizarro, M. Farras, R. de la Torre, I. Subirana, F. J. Perez-Cano, O. Castaner, R. Sola, S. Fernandez-Castillejo, S. Heredia, M. Farre, M. J. Motilva and M. Fito, Effect of virgin olive oil and thyme phenolic compounds on blood lipid profile: implications of human gut microbiota, Eur. J. Nutr., 2017, 56, 119-131.

77 S. Martin-Pelaez, O. Castaner, R. Sola, M. J. Motilva, M. Castell, F. J. Perez-Cano and M. Fito, Influence of Phenol-Enriched Olive Oils on Human Intestinal Immune Function, Nutrients, 2016, 8, 213.

78 L. Conterno, F. Martinelli, M. Tamburini, F. Fava, A. Mancini, M. Sordo, M. Pindo, S. Martens, D. Masuero, U. Vrhovsek, C. Dal Lago, G. Ferrario, M. Morandini and K. Tuohy, Measuring the impact of olive pomace enriched biscuits on the gut microbiota and its metabolic activity in mildly hypercholesterolaemic subjects, Eur. J. Nutr., 2017, DOI: 10.1007/s00394-017-1572-2.

79 M. Farras, O. Castaner, S. Martin-Pelaez, A. Hernaez, H. Schroder, I. Subirana, D. Munoz-Aguayo, S. Gaixas, L. Torre Rde, M. Farre, L. Rubio, O. Diaz, S. FernandezCastillejo, R. Sola, M. J. Motilva and M. Fito, Complementary phenol-enriched olive oil improves HDL characteristics in hypercholesterolemic subjects. A randomized, double-blind, crossover, controlled trial. The VOHF study, Mol. Nutr. Food Res., 2015, 59, 1758-1770.

80 F. Biasi, M. Astegiano, M. Maina, G. Leonarduzzi and G. Poli, Polyphenol supplementation as a complementary medicinal approach to treating inflammatory bowel disease, Curr. Med. Chem., 2011, 18, 4851-4865.

81 A. Incani, G. Serra, A. Atzeri, M. P. Melis, G. Serreli, G. Bandino, P. Sedda, M. Campus, C. I. Tuberoso and M. Deiana, Extra virgin olive oil phenolic extracts counteract the pro-oxidant effect of dietary oxidized lipids in human intestinal cells, Food Chem. Toxicol., 2016, 90, 171-180.
82 J. P. De La Cruz, M. I. Ruiz-Moreno, A. Guerrero, J. A. Lopez-Villodres, J. J. Reyes, J. L. Espartero, M. T. Labajos and J. A. Gonzalez-Correa, Role of the catechol group in the antioxidant and neuroprotective effects of virgin olive oil components in rat brain, J. Nutr. Biochem., 2015, 26, 549-555.

83 F. Visioli, A. Poli and C. Gall, Antioxidant and other biological activities of phenols from olives and olive oil, Med. Res. Rev., 2002, 22, 65-75.

84 M. Deiana, G. Corona, A. Incani, D. Loru, A. Rosa, A. Atzeri, M. P. Melis and M. A. Dessi, Protective effect of simple phenols from extravirgin olive oil against lipid peroxidation in intestinal Caco-2 cells, Food Chem. Toxicol., 2010, 48, 3008-3016.

85 C. Manna, P. Galletti, V. Cucciolla, O. Moltedo, A. Leone and V. Zappia, The protective effect of the olive oil polyphenol (3,4-dihydroxyphenyl)-ethanol counteracts reactive oxygen metabolite-induced cytotoxicity in Caco-2 cells, J. Nutr., 1997, 127, 286-292.

86 I. Rodriguez-Ramiro, M. A. Martin, S. Ramos, L. Bravo and L. Goya, Olive oil hydroxytyrosol reduces toxicity evoked by acrylamide in human Caco- 2 cells by preventing oxidative stress, Toxicology, 2011, 288, 43-48.

87 A. Atzeri, R. Lucas, A. Incani, P. Penalver, A. Zafra-Gomez, M. P. Melis, R. Pizzala, J. C. Morales and M. Deiana, Hydroxytyrosol and tyrosol sulfate metabolites protect against the oxidized cholesterol pro-oxidant effect in Caco-2 human enterocyte-like cells, Food Funct., 2016, 7, 337-346.

88 M. Deiana, A. Incani, A. Rosa, A. Atzeri, D. Loru, B. Cabboi, M. Paola Melis, R. Lucas, J. C. Morales and M. Assunta Dessi, Hydroxytyrosol glucuronides protect renal tubular epithelial cells against $\mathrm{H}(2) \mathrm{O}(2)$ induced oxidative damage, Chem.-Biol. Interact., 2011, 193, 232-239.

89 F. Paiva-Martins, A. Silva, V. Almeida, M. Carvalheira, C. Serra, J. E. Rodrigues-Borges, J. Fernandes, L. Belo and A. Santos-Silva, Protective activity of hydroxytyrosol metabolites on erythrocyte oxidative-induced hemolysis, J. Agric. Food Chem., 2013, 61, 6636-6642.

90 C. Giovannini, E. Straface, D. Modesti, E. Coni, A. Cantafora, M. De Vincenzi, W. Malorni and R. Masella, Tyrosol, the major olive oil biophenol, protects against oxidized-LDL-induced injury in Caco-2 cells, J. Nutr., 1999, 129, 1269-1277.

91 V. R. Gutierrez, R. de la Puerta and A. Catala, The effect of tyrosol, hydroxytyrosol and oleuropein on the non-enzymatic lipid peroxidation of rat liver microsomes, Mol. Cell. Biochem., 2001, 217, 35-41.

92 A. A. Bertelli, M. Migliori, V. Panichi, B. Longoni, N. Origlia, A. Ferretti, M. G. Cuttano and L. Giovannini, Oxidative stress and inflammatory reaction modulation by white wine, Ann. N. Y. Acad. Sci., 2002, 957, 295-301.

93 R. de la Puerta, M. E. Martinez Dominguez, V. RuizGutierrez, J. A. Flavill and J. R. Hoult, Effects of virgin olive oil phenolics on scavenging of reactive nitrogen 
species and upon nitrergic neurotransmission, Life Sci., 2001, 69, 1213-1222.

94 M. A. Martin, S. Ramos, A. B. Granado-Serrano, I. Rodriguez-Ramiro, M. Trujillo, L. Bravo and L. Goya, Hydroxytyrosol induces antioxidant/detoxificant enzymes and Nrf2 translocation via extracellular regulated kinases and phosphatidylinositol-3-kinase/protein kinase B pathways in HepG2 cells, Mol. Nutr. Food Res., 2010, 54, 956966.

95 E. Giordano, A. Davalos and F. Visioli, Chronic hydroxytyrosol feeding modulates glutathione-mediated oxidoreduction pathways in adipose tissue: A nutrigenomic study, Nutr., Metab. Cardiovasc. Dis., 2014, 24, 1144-1150.

96 K. Cao, J. Xu, X. Zou, Y. Li, C. Chen, A. Zheng, H. Li, I. M. Szeto, Y. Shi, J. Long, J. Liu and Z. Feng, Hydroxytyrosol prevents diet-induced metabolic syndrome and attenuates mitochondrial abnormalities in obese mice, Free Radical Biol. Med., 2014, 67, 396-407.

97 L. Zhu, Z. B. Liu, Z. H. Feng, J. J. Hao, W. L. Shen, X. S. Li, L. J. Sun, E. Sharman, Y. Wang, K. Wertz, P. Weber, X. L. Shi and J. K. Liu, Hydroxytyrosol protects against oxidative damage by simultaneous activation of mitochondrial biogenesis and phase II detoxifying enzyme systems in retinal pigment epithelial cells, J. Nutr. Biochem., 2010, 21, 1089-1098.

98 I. Fki, Z. Sahnoun and S. Sayadi, Hypocholesterolemic effects of phenolic extracts and purified hydroxytyrosol recovered from olive mill wastewater in rats fed a cholesterol-rich diet, J. Agric. Food Chem., 2007, 55, 624-631.

99 M. C. Crespo, J. Tome-Carneiro, E. Burgos-Ramos, V. Loria Kohen, M. I. Espinosa, J. Herranz and F. Visioli, One-week administration of hydroxytyrosol to humans does not activate Phase II enzymes, Pharmacol. Res., 2015, 95-96, 132-137.

100 F. J. G. Muriana, S. Montserrat-de la Paz, R. Lucas, B. Bermudez, S. Jaramillo, J. C. Morales, R. Abia and S. Lopez, Tyrosol and its metabolites as antioxidative and anti-inflammatory molecules in human endothelial cells, Food Funct., 2017, 8, 2905-2914.

101 R. Di Benedetto, R. Vari, B. Scazzocchio, C. Filesi, C. Santangelo, C. Giovannini, P. Matarrese, M. D'Archivio and R. Masella, Tyrosol, the major extra virgin olive oil compound, restored intracellular antioxidant defences in spite of its weak antioxidative effectiveness, Nutr., Metab. Cardiovasc. Dis., 2007, 17, 535-545.

102 W. C. Wang, Y. M. Xia, B. Yang, X. N. Su, J. K. Chen, W. Li and T. Jiang, Protective Effects of Tyrosol against LPS-Induced Acute Lung Injury via Inhibiting NF-kappa B and AP-1 Activation and Activating the HO-1/Nrf2 Pathways, Biol. Pharm. Bull., 2017, 40, 583-593.

103 I. Hassen, H. Casabianca and K. Hosni, Biological activities of the natural antioxidant oleuropein: Exceeding the expectation - A mini-review, J. Funct. Foods, 2015, 18, 926940.

104 A. Parzonko, M. E. Czerwinska, A. K. Kiss and M. Naruszewicz, Oleuropein and oleacein may restore biological functions of endothelial progenitor cells impaired by angiotensin II via activation of Nrf2/heme oxygenase-1 pathway, Phytomedicine, 2013, 20, 1088-1094.

105 C. Shi, X. Chen, Z. Liu, R. Meng, X. Zhao and N. Guo, Oleuropein protects L-02 cells against $\mathrm{H} 2 \mathrm{O} 2$-induced oxidative stress by increasing SOD1, GPx1 and CAT expression, Biomed. Pharmacother., 2017, 85, 740-748.

106 H. Jemai, M. Bouaziz, I. Fki, A. El Feki and S. Sayadi, Hypolipidimic and antioxidant activities of oleuropein and its hydrolysis derivative-rich extracts from Chemlali olive leaves, Chem.-Biol. Interact., 2008, 176, 88-98.

107 D. Kotyzova, A. Hodkova and V. Eybl, The effect of olive oil phenolics - Hydroxytyrosol and oleuropein on antioxidant defence status in acute arsenic exposed rats, Toxicol. Lett., 2011, 205, S222-S222.

108 W. Sun, X. Wang, C. Hou, L. Yang, H. Li, J. Guo, C. Huo, M. Wang, Y. Miao, J. Liu and Y. Kang, Oleuropein improves mitochondrial function to attenuate oxidative stress by activating the Nrf2 pathway in the hypothalamic paraventricular nucleus of spontaneously hypertensive rats, Neuropharmacology, 2017, 113, 556-566.

109 M. Sarbishegi, F. Mehraein and M. Soleimani, Antioxidant role of oleuropein on midbrain and dopaminergic neurons of substantia nigra in aged rats, Iran. Biomed. J., 2014, 18, 16-22.

110 H. F. Al-Azzawie and M. S. S. Alhamdani, Hypoglycemic and antioxidant effect of oleuropein in alloxan-diabetic rabbits, Life Sci., 2006, 78, 1371-1377.

111 A. Cardeno, M. Sanchez-Hidalgo and C. Alarcon-de-laLastra, An up-date of olive oil phenols in inflammation and cancer: molecular mechanisms and clinical implications, Curr. Med. Chem., 2013, 20, 4758-4776.

112 E. Muto, M. Dell'Agli, E. Sangiovanni, N. Mitro, M. Fumagalli, M. Crestani, E. De Fabiani and D. Caruso, Olive oil phenolic extract regulates interleukin-8 expression by transcriptional and posttranscriptional mechanisms in Caco-2 cells, Mol. Nutr. Food Res., 2015, 59, 1217-1221.

113 G. Serra, A. Incani, G. Serreli, L. Porru, M. P. Melis, C. I. G. Tuberoso, D. Rossin, F. Biasi and M. Deiana, Olive oil polyphenols reduce oxysterols -induced redox imbalance and pro-inflammatory response in intestinal cells, Redox Biol., 2018, 17, 348-354.

114 S. Sanchez-Fidalgo, A. Cardeno, M. Sanchez-Hidalgo, M. Aparicio-Soto and C. A. de la Lastra, Dietary extra virgin olive oil polyphenols supplementation modulates DSS-induced chronic colitis in mice, J. Nutr. Biochem., 2013, 24, 1401-1413.

115 S. Sanchez-Fidalgo, A. Cardeno, M. Sanchez-Hidalgo, M. Aparicio-Soto, I. Villegas, M. A. Rosillo and C. A. de la Lastra, Dietary unsaponifiable fraction from extra virgin olive oil supplementation attenuates acute ulcerative colitis in mice, Eur. J. Pharm. Sci., 2013, 48, 572-581.

116 E. Giner, I. Andujar, M. C. Recio, J. L. Rios, J. M. CerdaNicolas and R. M. Giner, Oleuropein ameliorates acute colitis in mice, J. Agric. Food Chem., 2011, 59, 1288212892. 
117 E. Giner, M. C. Recio, J. L. Rios and R. M. Giner, Oleuropein protects against dextran sodium sulfateinduced chronic colitis in mice, J. Nat. Prod., 2013, 76, 1113-1120.

118 E. Giner, M. C. Recio, J. L. Rios, J. M. Cerda-Nicolas and R. M. Giner, Chemopreventive effect of oleuropein in colitis-associated colorectal cancer in c57bl/6 mice, Mol. Nutr. Food Res., 2016, 60, 242-255.

119 T. Larussa, M. Oliverio, E. Suraci, M. Greco, R. Placida, S. Gervasi, R. Marasco, M. Imeneo, D. Paolino, L. Tucci, E. Gulletta, M. Fresta, A. Procopio and F. Luzza, Oleuropein Decreases Cyclooxygenase-2 and Interleukin17 Expression and Attenuates Inflammatory Damage in Colonic Samples from Ulcerative Colitis Patients, Nutrients, 2017, 9, 391.

120 A. Voltes, A. Bermudez, G. Rodriguez-Gutierrez, M. L. Reyes, C. Olano, J. Fernandez-Bolanos and F. Portilla, Anti-Inflammatory Local Effect of Hydroxytyrosol Combined with Pectin-Alginate and Olive Oil on Trinitrobenzene Sulfonic Acid-Induced Colitis in Wistar Rats, J. Invest. Surg., 2018, 1-7.

121 S. Sanchez-Fidalgo, L. Sanchez de Ibarguen, A. Cardeno and C. Alarcon de la Lastra, Influence of extra virgin olive oil diet enriched with hydroxytyrosol in a chronic DSS colitis model, Eur. J. Nutr., 2012, 51, 497-506.

122 G. Corona, M. Deiana, A. Incani, D. Vauzour, M. A. Dessi and J. P. Spencer, Inhibition of p38/CREB phosphorylation and COX-2 expression by olive oil polyphenols underlies their anti-proliferative effects, Biochem. Biophys. Res. Commun., 2007, 362, 606-611.

123 S. Sanchez-Fidalgo, I. Villegas, M. Aparicio-Soto, A. Cardeno, M. A. Rosillo, A. Gonzalez-Benjumea, A. Marset, O. Lopez, I. Maya, J. G. Fernandez-Bolanos and C. Alarcon de la Lastra, Effects of dietary virgin olive oil polyphenols: hydroxytyrosyl acetate and 3, 4-dihydroxyphenylglycol on DSS-induced acute colitis in mice, J. Nutr. Biochem., 2015, 26, 513-520.

124 L. Parkinson and R. Keast, Oleocanthal, a phenolic derived from virgin olive oil: a review of the beneficial effects on inflammatory disease, Int. J. Mol. Sci., 2014, 15, 12323-12334.

125 C. Pelucchi, C. Bosetti, E. Negri, L. Lipworth and C. La Vecchia, Olive oil and cancer risk: an update of epidemiological findings through 2010, Curr. Pharm. Des., 2011, 17, 805-812.

126 F. Levi, C. Pasche, C. La Vecchia, F. Lucchini and S. Franceschi, Food groups and colorectal cancer risk, Br. J. Cancer, 1999, 79, 1283-1287.

127 M. Stoneham, M. Goldacre, V. Seagroatt and L. Gill, Olive oil, diet and colorectal cancer: an ecological study and a hypothesis, J. Epidemiol. Community Health, 2000, 54, 756-760.

128 T. Psaltopoulou, R. I. Kosti, D. Haidopoulos, M. Dimopoulos and D. B. Panagiotakos, Olive oil intake is inversely related to cancer prevalence: a systematic review and a meta-analysis of 13800 patients and 23340 controls in 19 observational studies, Lipids Health Dis., 2011, 10, 127.

129 A. Farinetti, V. Zurlo, A. Manenti, F. Coppi and A. V. Mattioli, Mediterranean diet and colorectal cancer: A systematic review, Nutrition, 2017, 43-44, 83-88.

130 J. A. Menendez and R. Lupu, Mediterranean dietary traditions for the molecular treatment of human cancer: anti-oncogenic actions of the main olive oil's monounsaturated fatty acid oleic acid (18:1n-9), Curr. Pharm. Biotechnol., 2006, 7, 495-502.

131 R. W. Owen, A. Giacosa, W. E. Hull, R. Haubner, B. Spiegelhalder and H. Bartsch, The antioxidant/anticancer potential of phenolic compounds isolated from olive oil, Eur. J. Cancer, 2000, 36, 1235-1247.

132 E. Middleton Jr., C. Kandaswami and T. C. Theoharides, The effects of plant flavonoids on mammalian cells: implications for inflammation, heart disease, and cancer, Pharmacol. Rev., 2000, 52, 673-751.

133 G. Corona, J. P. Spencer and M. A. Dessi, Extra virgin olive oil phenolics: absorption, metabolism, and biological activities in the GI tract, Toxicol. Ind. Health, 2009, 25, 285-293.

134 I. Casaburi, F. Puoci, A. Chimento, R. Sirianni, C. Ruggiero, P. Avena and V. Pezzi, Potential of olive oil phenols as chemopreventive and therapeutic agents against cancer: a review of in vitro studies, Mol. Nutr. Food Res., 2013, 57, 71-83.

135 S. J. Duthie and V. L. Dobson, Dietary flavonoids protect human colonocyte DNA from oxidative attack in vitro, Eur. J. Nutr., 1999, 38, 28-34.

136 L. Sun, C. Luo and J. Liu, Hydroxytyrosol induces apoptosis in human colon cancer cells through ROS generation, Food Funct., 2014, 5, 1909-1914.

137 J. O. Moskaug, H. Carlsen, M. C. Myhrstad and R. Blomhoff, Polyphenols and glutathione synthesis regulation, Am. J. Clin. Nutr., 2005, 81, 277S-283S.

138 G. M. Safonova, Y. Shilov and A. B. Perevozchikov, Protective effects of plant polyphenols on the immune system in acute stress, Dokl. Biol. Sci, 2001, 378, 233-235.

139 M. Calomme, L. Pieters, A. Vlietinck and D. Vanden Berghe, Inhibition of bacterial mutagenesis by Citrus flavonoids, Planta Med., 1996, 62, 222-226.

140 L. D. Banks, P. Amoah, M. S. Niaz, M. K. Washington, S. E. Adunyah and A. Ramesh, Olive oil prevents benzo(a) pyrene $[\mathrm{B}(\mathrm{a}) \mathrm{P}]$-induced colon carcinogenesis through altered $\mathrm{B}(\mathrm{a}) \mathrm{P}$ metabolism and decreased oxidative damage in Apc (Min) mouse model, J. Nutr. Biochem., 2016, 28, 37-50.

141 B. Plaumann, M. Fritsche, H. Rimpler, G. Brandner and R. D. Hess, Flavonoids activate wild-type p53, Oncogene, 1996, 13, 1605-1614.

142 G. Corona, M. Deiana, A. Incani, D. Vauzour, M. A. Dessi and J. P. Spencer, Hydroxytyrosol inhibits the proliferation of human colon adenocarcinoma cells through inhibition of ERK1/2 and cyclin D1, Mol. Nutr. Food Res., 2009, 53, 897-903.

143 M. J. van Erk, P. Roepman, T. R. van der Lende, R. H. Stierum, J. M. Aarts, P. J. van Bladeren and B. van 
Ommen, Integrated assessment by multiple gene expression analysis of quercetin bioactivity on anticancerrelated mechanisms in colon cancer cells in vitro, Eur. J. Nutr., 2005, 44, 143-156.

144 A. Di Francesco, A. Falconi, C. Di Germanio, M. V. Micioni Di Bonaventura, A. Costa, S. Caramuta, M. Del Carlo, D. Compagnone, E. Dainese, C. Cifani, M. Maccarrone and C. D'Addario, Extravirgin olive oil up-regulates $\mathrm{CB}(1)$ tumor suppressor gene in human colon cancer cells and in rat colon via epigenetic mechanisms, J. Nutr. Biochem., 2015, 26, 250-258.

145 X. Llor, E. Pons, A. Roca, M. Alvarez, J. Mane, F. Fernandez-Banares and M. A. Gassull, The effects of fish oil, olive oil, oleic acid and linoleic acid on colorectal neoplastic processes, Clin. Nutr., 2003, 22, 71-79.

146 R. Bartoli, F. Fernandez-Banares, E. Navarro, E. Castella, J. Mane, M. Alvarez, C. Pastor, E. Cabre and M. A. Gassull, Effect of olive oil on early and late events of colon carcinogenesis in rats: modulation of arachidonic acid metabolism and local prostaglandin E(2) synthesis, Gut, 2000, 46, 191-199.

147 S. Sieri, C. Agnoli, V. Pala, A. Mattiello, S. Panico, G. Masala, M. Assedi, R. Tumino, G. Frasca, C. Sacerdote, P. Vineis and V. Krogh, Dietary habits and cancer: the experience of EPIC-Italy, Epidemiol. Prev., 2015, 39, 333-338.

148 M. Solanas, A. Hurtado, I. Costa, R. Moral, J. A. Menendez, R. Colomer and E. Escrich, Effects of a high olive oil diet on the clinical behavior and histopathological features of rat DMBA-induced mammary tumors compared with a high corn oil diet, Int. J. Oncol., 2002, 21, 745-753.

149 C. I. Gill, A. Boyd, E. McDermott, M. McCann, M. Servili, R. Selvaggini, A. Taticchi, S. Esposto, G. Montedoro, H. McGlynn and I. Rowland, Potential anti-cancer effects of virgin olive oil phenols on colorectal carcinogenesis models in vitro, Int. J. Cancer, 2005, 117, 1-7.

150 Y. Z. Hashim, I. R. Rowland, H. McGlynn, M. Servili, R. Selvaggini, A. Taticchi, S. Esposto, G. Montedoro, L. Kaisalo, K. Wahala and C. I. Gill, Inhibitory effects of olive oil phenolics on invasion in human colon adenocarcinoma cells in vitro, Int. J. Cancer, 2008, 122, 495-500.

151 L. Fini, E. Hotchkiss, V. Fogliano, G. Graziani, M. Romano, E. B. De Vol, H. Qin, M. Selgrad, C. R. Boland and L. Ricciardiello, Chemopreventive properties of pinoresinol-rich olive oil involve a selective activation of the
ATM-p53 cascade in colon cancer cell lines, Carcinogenesis, 2008, 29(1), 139-146.

152 S. Chell, A. Kadi, A. C. Williams and C. Paraskeva, Mediators of PGE2 synthesis and signalling downstream of COX-2 represent potential targets for the prevention/ treatment of colorectal cancer, Biochim. Biophys. Acta, 2006, 1766, 104-119.

153 P. Khanal, W. K. Oh, H. J. Yun, G. M. Namgoong, S. G. Ahn, S. M. Kwon, H. K. Choi and H. S. Choi, p-HPEA-EDA, a phenolic compound of virgin olive oil, activates AMP-activated protein kinase to inhibit carcinogenesis, Carcinogenesis, 2011, 32, 545-553.

154 J. S. Sebolt-Leopold and R. Herrera, Targeting the mitogen-activated protein kinase cascade to treat cancer, Nat. Rev. Cancer, 2004, 4, 937-947.

155 C. Tsatsanis, A. Androulidaki, M. Venihaki and A. N. Margioris, Signalling networks regulating cyclooxygenase-2, Int. J. Biochem. Cell Biol., 2006, 38, 1654-1661.

156 R. Fabiani, A. De Bartolomeo, P. Rosignoli, M. Servili, G. F. Montedoro and G. Morozzi, Cancer chemoprevention by hydroxytyrosol isolated from virgin olive oil through G1 cell cycle arrest and apoptosis, Eur. J. Cancer Prev., 2002, 11, 351-358.

157 C. Guichard, E. Pedruzzi, M. Fay, J. C. Marie, F. BrautBoucher, F. Daniel, A. Grodet, M. A. Gougerot-Pocidalo, E. Chastre, L. Kotelevets, G. Lizard, A. Vandewalle, F. Driss and E. Ogier-Denis, Dihydroxyphenylethanol induces apoptosis by activating serine/threonine protein phosphatase PP2A and promotes the endoplasmic reticulum stress response in human colon carcinoma cells, Carcinogenesis, 2006, 27, 1812-1827.

158 C. Giovannini, B. Scazzocchio, P. Matarrese, R. Vari, M. D’Archivio, R. Di Benedetto, S. Casciani, M. R. Dessi, E. Straface, W. Malorni and R. Masella, Apoptosis induced by oxidized lipids is associated with up-regulation of p66Shc in intestinal Caco-2 cells: protective effects of phenolic compounds, J. Nutr. Biochem., 2008, 19, 118-128.

159 S. Purdom and Q. M. Chen, p66(Shc): at the crossroad of oxidative stress and the genetics of aging, Trends Mol. Med., 2003, 9, 206-210.

160 F. Visioli, M. Franco, E. Toledo, J. Luchsinger, W. C. Willett, F. B. Hu and M. A. Martinez-Gonzalez, Olive oil and prevention of chronic diseases: Summary of an International conference, Nutr., Metab. Cardiovasc. Dis., 2018, 28, 649-656. 